\title{
A modelling tool for PM10 exposure assessment: an application example
}

\author{
E. Angelino, M. P. Costa, E. Peroni \& C. Sala \\ Environmental Protection Agency of Lombardy Region, Italy
}

\begin{abstract}
A tool has been developed with the aim of calculating population exposure to PM10 concentrations. It integrates two main modules: a linker to the outputs of a chemistry and transport model (outdoor ambient concentrations) and a timevariable exposure module. The leading concept behind exposure modelling is that time-weighted average exposure can be considered as the sum of the partial exposures determined by both the concentration and the time spent in each so called micro-environment. A run of a CTM (Chemical and Transport Model) over the whole year of 2006 provided the PM10 hourly outdoor concentration field. In the absence of specifically measured data, some input data, such as infiltration parameters and indoor sources concentrations, have been chosen from relevant literature data. This paper reports the main input data used and the results obtained during an application to the domain under study, located in the North of Italy. The results confirm that the population habits and indoor sources contributions are the most critical parameters when assessing exposure.
\end{abstract}

Keywords: exposure modelling, particulate modelling, air quality management.

\section{Introduction}

A modelling system for exposure assessment must be able to integrate numerous and various pieces of information such as land use, emissions, meteorology, dispersion and chemical reactions of pollutants, population activity patterns and distribution. In recent years a growing integration of all this information, generally obtained by employing different and separate models in the past, into more sophisticated and comprehensive modelling systems has occurred. In the past, US modelling groups have supported the most comprehensive efforts in this area (Seigneur [14], Burke et al [3]), but recent European efforts have also 
produced interesting experiences in many parts of Europe. The FUMAPEX project [6] gives a wide overview of exposure modelling assessment applications, characterised by different approaches and computational tools, input data sources, spatial and temporal resolution in relation to their final use and output dissemination media.

\section{Methodology}

A methodology for determination of population exposure using modelling techniques and air pollution observations has been developed in the framework of a research project carried out by ARPA Lombardia and supported by the APAT (Italian National Environmental Protection Agency). Exposure computation is based on the algorithm of eqn. (1):

$$
E=\frac{1}{t_{\text {avg }}} \sum_{i=1}^{n} t_{i} \times C_{i}=\sum_{i=1}^{n} f_{i} \times C_{i},
$$

where $E$ is a time-weighted average exposure level across the visited microenvironments $(i)$ calculated as the sum of partial exposures in each one of them. The partial exposures are calculated by multiplying the microenvironment concentration by the fraction of time $(f)$ spent in there. This approach assumes that a person's time-integrated exposure is the combination of the concentrations of a specific set of micro-environments, concentrations that are considered to be constant and homogeneous. Concentration in the indoor and in-vehicle microenvironments are calculated by separating ambient and indoor generated PM levels by the following equation as in Hänninen et al [8]:

$$
C_{i g}=C_{i}-C_{a i}
$$

where $C_{i}\left(\mu \mathrm{g} / \mathrm{m}^{3}\right)$ is the total indoor concentration, $C_{a i}\left(\mu \mathrm{g} / \mathrm{m}^{3}\right)$ the contribution from ambient outdoor concentration that has infiltrated indoors and $C_{i g}\left(\mu \mathrm{g} / \mathrm{m}^{3}\right)$ the concentrations caused by indoor sources. On the basis of the steady-state mass balance equation, assuming uniform mixing within the building and steady state conditions, i.e. that the penetration efficiency $P$ (unitless), the air exchange rate $a\left(\mathrm{~h}^{-1}\right)$ and the indoor decay rate $K\left(\mathrm{~h}^{-1}\right)$ do not change with time, then concentration fractions in eqn (2) can be expressed as:

$$
C_{i g}=\frac{Q}{V(a+k)}, \quad C_{a i}=\frac{P \cdot a}{a+k} C_{a},
$$

where $Q$ represents the source strength $\left(\mu \mathrm{g} \mathrm{h}^{-1}\right)$, and $V$ the interior volume of the building $\left(\mathrm{m}^{3}\right)$. By defining the indoor-outdoor ratio of the ambient pollutant concentration $\left(C_{a i} / C_{a}\right)$ as an infiltration factor $\left(F_{i n f}\right)$, it is possible to express the indoor concentration as:

$$
C_{i}=C_{i g}+C_{a i}=C_{i g}+F_{i n f} C_{a}
$$


Combining (1) and (4), exposure can be computed as:

$$
\bar{E}=\frac{1}{t_{\text {avg }}} \sum_{i=1}^{n} t_{i} \times C_{i}=\sum_{i=1}^{n} f_{i} \times\left(F_{\text {inf }} C_{a}+C_{i g}\right) .
$$

The outdoor ambient concentrations can be estimated from monitoring data or simulated by an air quality model. $F_{\text {inf }}$ and $C_{i g}$ can be derived using regression of concurrent indoor and outdoor PM measurements. To date several experimental studies have been performed aiming to quantify how much outdoor sources contributed to the indoor concentrations and to characterise the air exchange rate, in relation to the building insulating materials, home or vehicle ventilation habits, seasonal factors etc. Attention has been paid also on estimation of indoor PM sources (cigarette smoking, wood burning, house work such as cooking, dusting, carpet cleaning, spraying such as using paints, cleaners and other consumer products in spray). Among the most relevant ones, the following studies can be mentioned: the Harvard six cities study (Dockery and Spengler [5]), the New York State ERDA (Koutrakis et al [11]), the Particle Total Exposure Assessment Methodology Study (PTEAM) conducted in California (Ozkaynak et al [13]), the characterisation of indoor particle sources in Boston (Abt et al [1]), the European EXPOLIS (Hänninen et al [8]), the Relation among Indoor, Outdoor and Personal Air (RIOPA) (Weisel et al [18]), the NERL residential ultrafine, fine and coarse PM study (Wallace et al [17]). Several papers give brief descriptions of them and summarise the main results (Wallace [16], Hänninen et al [8], Georgopoulos et al [7], Monn [12], Jantunen et al [10]).

\section{The modelling tool}

The modelling tool, represented in figure 1, is composed of two main subsystems. The air quality modelling system is based on the FARM Eulerian chemical transport model (Flexible Air quality Regional Model, Silibello et al. [15]); the other components of the system are two pre-processors used to reconstruct flows and turbulence parameters, an emission pre-processor and a module preparing the initial and boundary concentrations from a large scale model results and observational data. In this study, the FARM model has been applied with the SAPRC-90 gas-phase chemical mechanism and the CMAQ aero3 modal aerosol module. The exposure modelling subsystem is based on equation (4) and has the following characteristics: the population is divided into several groups with specific activity patterns; the study area can be divided into several zones (including one or grouped municipalities).

A GIS module allocates population to the air quality field grid cells; the population dynamics follow the movement of a population group both through different microenvironments and different zones as a function of time. Infiltration factors can be specified both for zones and for each transit/indoor micro-environment. For each of them concentrations are calculated on the basis of both outdoor concentrations and contributions from selected indoor sources. 


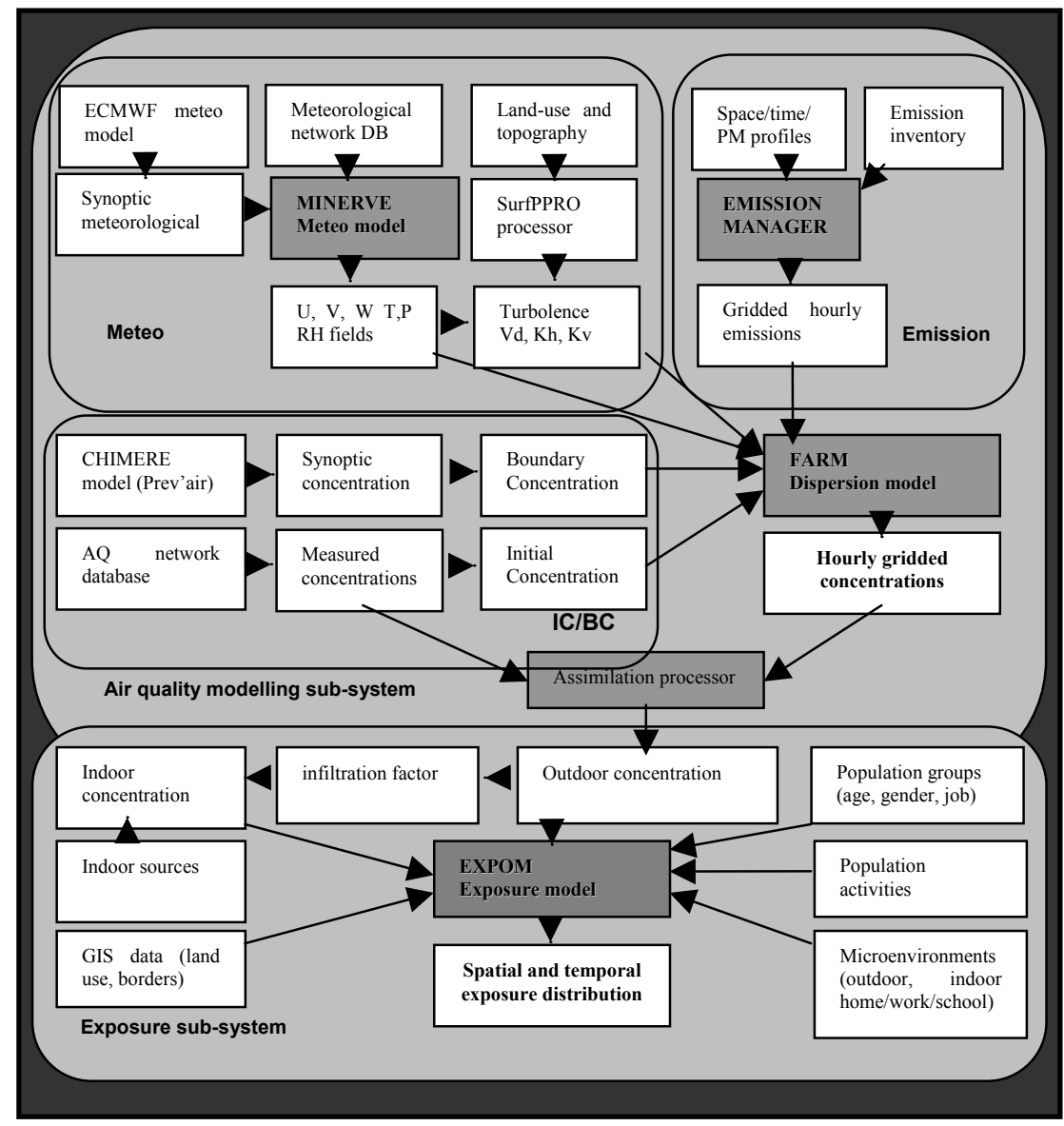

Figure 1: Modelling system used in the study.

\section{Input data}

To compute the outdoor concentration field an hourly run of the air quality modelling system has been done over the whole 2006 year (Silibello et al [15]). The system has been applied to a $4 \mathrm{Km}$ cell-size 244 x $236 \mathrm{~km}^{2}$ domain, including the whole Lombardy region, in the Po-Valley Basin in Northern Italy. The hourly meteorological fields were obtained from the meteorological ARPA Lombardia network and from ECMWF synoptic model fields; the boundary and initial conditions were provided by the Prev'air system (www.prevair.org) based on the CHIMERE model; the emission inputs were derived from the regional INEMAR 2003 emission inventory. Different assimilation procedures have been tested and used to guarantee consistency with observations. In this application the tool was run for six different population groups: "class 1": infants (0-3 
years), "class 2": schoolchildren (3-14 years), "class 3": youths (15-24 years), "class 4": younger adults (25-34 years), "class 5": adults (35-64 years), "class 6": elderly people (over 64 years). Four microenvironments have been considered: "1" indoor home, "2" indoor work/school/other, "3" transit, "4" outdoor. In the absence of local measured data, concentrations for each indoor microenvironment have been derived as a function of ambient concentrations plus a contribution due to indoor sources. The infiltration parameters and indoor sources concentrations were chosen from range values shown by the previously mentioned literature. The infiltration factors selected for the application were: 0.8 for indoor micro-environments, 0.9 for transit, 1 for outdoor. Each microenvironment and each population group were associated to two sets of time profiles, inferred from data collected during a survey by the Italian National Statistical Institute ISTAT [9] and from the EXPOLIS project over the city of Milan. In both cases, the only available data is the total average amount of time spent in a specific activity or environment, without further specification on which hours of the day are dedicated to each. As a consequence, the profiles were arbitrarily set up making reasonable assumptions on which hours to assign to each microenvironment, and then making sure that the total number of hours matched the available data. In Figure 1 and Figure 2 the profiles are represented by a set of rectangles with varying height: a height of 1 indicates that in the corresponding hour of the day the population class resides in microenvironment "indoor home", 2 indicates "indoor work/school/other", 3 "transit", 4 "outdoor".
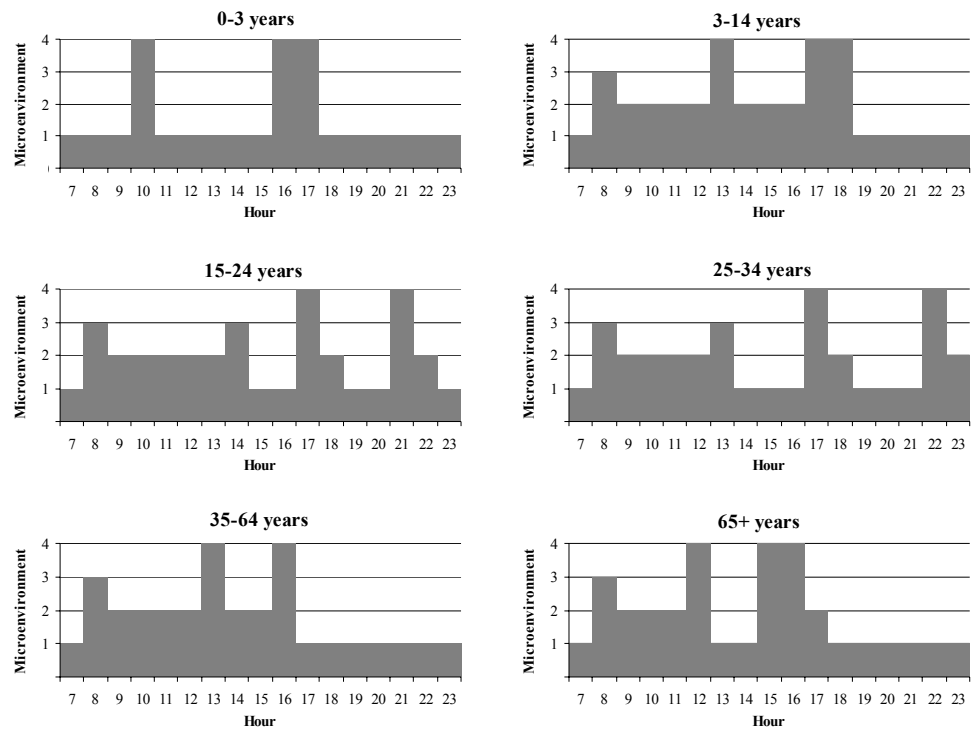

Figure 2: Time profiles from ISTAT data. 

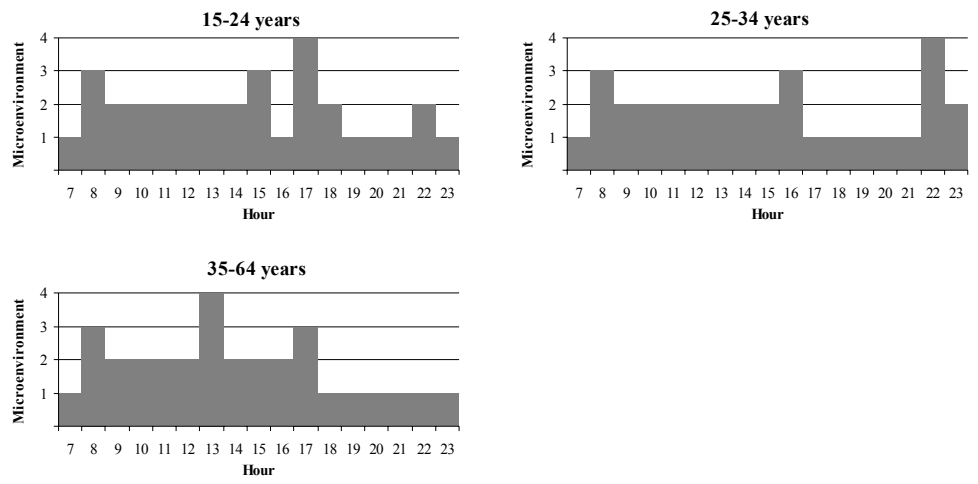

Figure 3: Time profiles from EXPOLIS data, only for the classes that differ from ISTAT.

\section{Results}

The tool was first fed with the ISTAT time profiles, obtaining a base case result to use as a reference for the following tests. By modifying the profiles according to the EXPOLIS data, the resulting overall exposure reduces. This is reasonable considering that the amount of time spent outdoors is higher according to ISTAT, and that in the absence of indoor sources, as supposed in this case, this will lead to higher levels of average exposure. The two tests were then repeated under different assumptions:

- $\quad$ two indoor sources were introduced: a $50 \mu \mathrm{g} / \mathrm{m}^{3}$ source between 7 and 8 pm for cooking, and a $20 \mu \mathrm{g} / \mathrm{m}^{3}$ source between 7 and 8 am for personal care.

- the infiltration factor for microenvironment 2 (indoor work/school/other) was reduced to the value of 0.5 , in the hypothesis that homes are less insulated than workplaces, schools and public places.

The reduction pattern of the EXPOLIS-driven exposure values comparing to the ISTAT ones is confirmed (Figure 4), with the greatest variations occurring when the number of hours affected by the change is greater, as in the last test. The exposure distribution pattern is quite close to the PM10 modelled outdoor yearly average concentration (Figure 5); this follows from the assumption that has been made, i.e. the same population habits have been applied to the whole domain and no internal dynamics - shifts occurring from one concentration area to another, as when commuting - have been considered. In order to set up more detailed test cases, values of indoor source concentration due to household activities have been taken from Wallace [16]. They are probably not well related to the Italian lifestyle, but they can help one to understand the effect of indoor sources on the total exposure. A total of 12 model runs divided into three groups have been performed. For each group, only one kind of source was separately activated in the first three tests, while on the fourth all of them were taken into account in calculating the exposure (Table 1). 


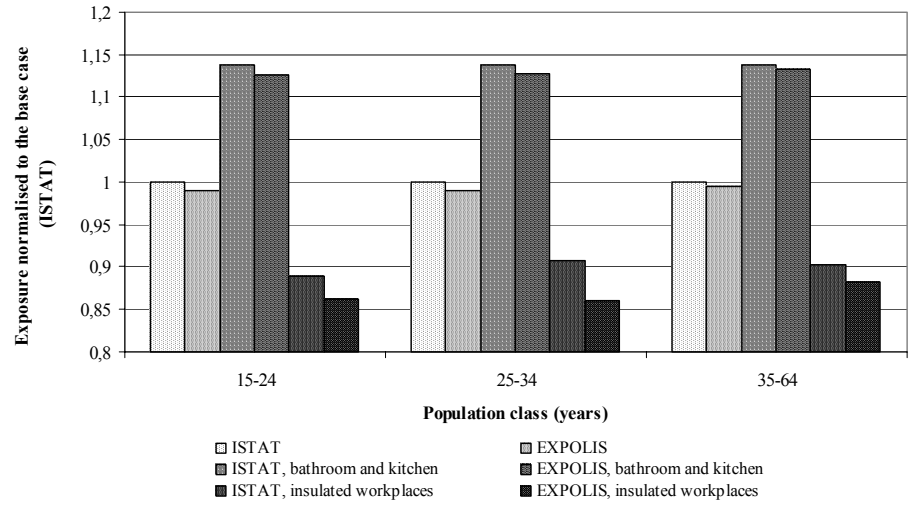

Figure 4: $\quad$ Population class average exposure, normalised to the base case.
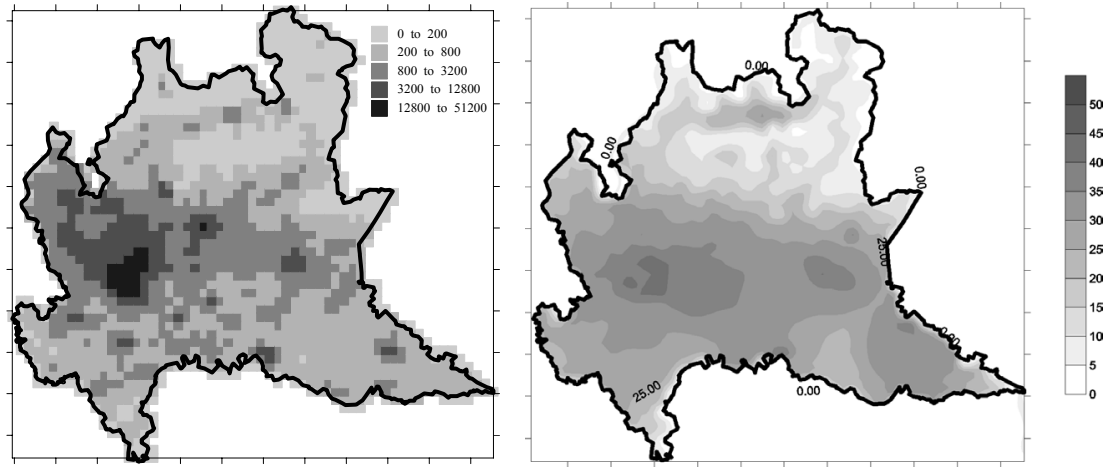

Figure 5: Population distribution and PM10 average exposure values over the study domain for class 3 under base case conditions.

Table 1: Indoor source tests.

\begin{tabular}{|c|c|c|c|}
\hline Indoor source & TEST A & TEST B & TEST C \\
\hline Cooking & $\begin{array}{c}50 \mu \mathrm{g} / \mathrm{m}^{3} \\
7-8 \mathrm{pm} \text { for all classes }\end{array}$ & $\begin{array}{c}\text { Same as test A, } 50 \% \\
\text { concentration reduction }\end{array}$ & $\begin{array}{c}50 \mu \mathrm{g} / \mathrm{m}^{3} \text { 7-8 am and } \\
7-8 \mathrm{pm} \text { for all classes }\end{array}$ \\
\hline Personal care & $\begin{array}{c}20 \mu \mathrm{g} / \mathrm{m}^{3} \\
7-8 \mathrm{am} \text { for all classes }\end{array}$ & $\begin{array}{c}\text { Same as test } \mathrm{A}, 50 \% \\
\text { concentration reduction }\end{array}$ & $\begin{array}{c}20 \mu \mathrm{g} / \mathrm{m}^{3} 7-8 \text { am and } \\
9-10 \mathrm{pm} \text { for all classes }\end{array}$ \\
\hline $\begin{array}{c}\text { Household } \\
\text { cleaning }\end{array}$ & $\begin{array}{c}30 \mu \mathrm{g} / \mathrm{m}^{3} \text { in the } \\
\text { morning working hours } \\
\text { for classes } 4 \text { and } 5\end{array}$ & $\begin{array}{c}\text { Same as test } \mathrm{A}, 50 \% \\
\text { concentration } \\
\text { reduction }\end{array}$ & $\begin{array}{c}30 \mu \mathrm{g} / \mathrm{m}^{3} \\
8-9 \text { am for all classes }\end{array}$ \\
\hline
\end{tabular}



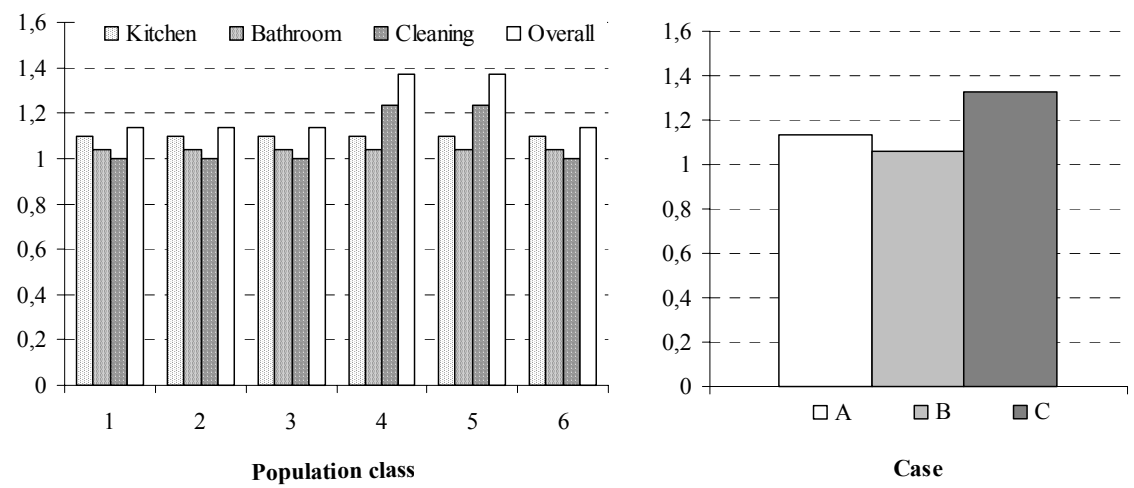

Figure 6: Household activities indoor sources: exposure normalised to the base case. Left: case A runs. Right: cases A, B, C for class 6, with all sources activated.

Figure 6, on the left, shows that the exposure values (normalised to the base case, where no indoor sources were included) correctly reflect the presence of different indoor sources. Cooking ("Kitchen") and personal care ("Bathroom") activities take just one hour, causing only a slight and homogeneous increment in the exposure of all classes. In case A, household cleaning hours have been supposed to span a longer interval for class 4 and 5, and the exposure consequently rises more for the concerned classes, even if the concentration value due to this indoor source is lower than that due to other activities.

\section{Conclusions}

The proposed results give insight into indoor source contribution to PM10 exposure. The developed tool proved itself sensible to the variations introduced into the input data. The need for more detailed information on time profiles and indoor sources is evident, as these factors control the dependency of exposure on outdoor measured or modelled concentration. It must be said that the required information on people habits and home characteristics is expected to vary depending on the country/region where the tool is going to be applied; for this reason a great effort is needed in order to obtain quality data from local measuring campaigns and population surveys.

\section{Acknowledgments}

This work has been supported by the APAT (National Environmental Protection Agency). The authors would thank Tiziana Forte and Luciana Sinisi from APAT and Angelo Giudici from ARPA Lombardia for their useful suggestions, and Pierantonio Gusmini for his precious support to the project. 


\section{References}

[1] Abt, E., Suh, H.H., Catalano, P. \& Koutrakis, P., Relative contribution of outdoor and indoor particle sources to indoor concentrations. Environmental Science \& Technology, 34 (17), pp. 3579-3587, 2000.

[2] Brunekreef, B., Janssen N. A. H., de Hartog J. J., Oldenwening M., Meliefste K., Hoek G., Lanki T., Timonen K. L., Vallius M., Pekkanen J. \& Van Grieken R., Personal, Indoor, and Outdoor Exposures to PM2.5 and its components for groups of cardiovascular patients in Amsterdam and Helsinki. HEI Health Effects Institute Research Report, 127, 2005.

[3] Burke, J. M., A population exposure model for particulate matter: case study results for PM2.5 in Philadelphia, PA, 2001, Online http://epa.gov/heasd/pm/pdf/exposure-model-for-pm.pdf

[4] Carmichael, G. R., Uno I., Phandis M. J., Zhang Y. \& Sunwoo, Y., (1998) Tropospheric ozone production and transport in the springtime in east Asia. Journal of Geophysical Research J. Geophys. Res., 103, pp. 1064910671, 1998.

[5] Dockery, D.W. \& Spengler, J.D., Indoor-outdoor relationships of respirable sulfates and particles. Atmospheric Environment 1, 15, pp. 335343, 1981.

[6] FUMAPEX Integrated Systems for Forecasting Urban Meteorology, Air Pollution and Population Exposure - Refined and validated population exposure models, work package 7: Population exposure modelling, Deliverable D7.1 2003 Online http://fumapex.dmi.dk/.

[7] Georgopoulos, P.G., Jayjock, E., Sun, Q., Isukapalli, S.S., Kevrekidis, P.G., Lazaridis, M. \& Drossinos, Y., Mechanisms controlling the outdoor/indoor relationships of fine particle levels and characteristics Final Technical Report CERM: 2002-3 Prepared under United States Environmental Protection Agency (USEPA) STAR Grant R826768, 2002, Online http://ccl.rutgers.edu/reports/cerm

[8] Hänninen, O. O., Lebret E., Ilacqua V., Katsouyanni K., Kunzli N., Sram R.J \& Jantunen M., Infiltration of ambient $\mathrm{PM}_{2.5}$ and level of indoor generated non-ETS PM2.5 in residence of four European cities Atmospheric Environment, 38, pp.6411-6423, 2004.

[9] ISTAT Indagine multiscopo sulle famiglie "Aspetti della vita quotidiana". Anno 2005, Online www.istat.it/dati/catalogo/20070406_01/.

[10] Jantunen, M.J., Katsouyanni, K., Knoppel, H., Kunzli, N., Lebret, E., Maroni, M., Saarela, K., Sram, R. \& Zmirou, D., EXPOLIS Air Pollution Exposure in European Cities: the EXPOLIS study - Final Report, 2003, Online www.kt.fi/expolis.

[11] Koutrakis, P., Briggs, S. L. K. \& Leaderer, B.P., Source apportionment of indoor aerosols in Suffolk and Onondaga Counties, New York. Environmental Science and Technology, 26, 521-527, 1992.

[12] Monn, C., Exposure assessment of air pollutants: a review on spatial heterogeneity and indoor/outdoor/personal exposure to suspended 
particulate matter, nitrogen dioxide and ozone, Atmospheric Environment, 35, pp. 1-32, 2001.

[13] Ozkaynak, H., Xue, J., Spenler, J., Wallace, L., Pellizzari, E. \& Jenkins, P., Personal exposure to airborne particles and metals: results from the particle TEAM study in Riverside, California. Journal of Exposure Analysis and Environmental Epidemiology, 1, pp. 57-78, 1996.

[14] Seigneur C., Review of mathematical models for health risk assessment: VI. Population exposure, Environmental Software, 9, pp. 133-145, 1994.

[15] Silibello, C., Calori, G., Brusasca, G., Giudici, A., Angelino, E., Fossati, G., Peroni, E. \& Buganza, E., Modelling of PM10 concentrations over Milano urban area: validation and sensitivity analysis of two aerosol modules, Environmental Modelling \& Software, 23 (3), pp. 333-343, 2008.

[16] Wallace, L., Indoor particles: a review. Journal of Air and Waste Management Association, 46, pp.98-126, 1996.

[17] Wallace, L., Williams, R., Rea, A. \& Croghan, C., Continuous weeklong measurement of personal exposure and indoor concentrations of fine particles for 37 health-impaired North Carolina resident for up to four seasons, Atmospheric Environment, 40, pp. 399-414, 2006.

[18] Weisel, C.P., Zhang, J, Turpin, B.J., Morandi, M.T., Colome, S., Stock, T.H. \& Spektor, D.M., Research Report: Relationships of Indoor, Outdoor, and Personal Air (RIOPA). HEI Research Report 130, NUATRC Research Report 7, 2005, Online www.sph.uth.tmc.edu. 